\title{
Development of high temperature mechanical rig for characterizing the viscoplastic properties of alloys used in solid oxide cells
}

Tadesse Molla, Tesfaye; Greco, Fabio; Kwok, Kawai; Zielke, Philipp; Frandsen, Henrik Lund

Published in:

Journal of Testing and Evaluation

Link to article, DOI:

10.1520/JTE20170046

Publication date:

2018

Document Version

Peer reviewed version

Link back to DTU Orbit

Citation (APA):

Tadesse Molla, T., Greco, F., Kwok, K., Zielke, P., \& Frandsen, H. L. (2018). Development of high temperature mechanical rig for characterizing the viscoplastic properties of alloys used in solid oxide cells. Journal of Testing and Evaluation, 46(5). https://doi.org/10.1520/JTE20170046

\section{General rights}

Copyright and moral rights for the publications made accessible in the public portal are retained by the authors and/or other copyright owners and it is a condition of accessing publications that users recognise and abide by the legal requirements associated with these rights.

- Users may download and print one copy of any publication from the public portal for the purpose of private study or research.

- You may not further distribute the material or use it for any profit-making activity or commercial gain

- You may freely distribute the URL identifying the publication in the public portal 


\title{
Development of high temperature mechanical rig for characterizing the viscoplastic properties of alloys used in solid oxide cells
}

\author{
Tesfaye Tadesse Molla ${ }^{1}$, Fabio Greco, Kawai Kwok*, Philipp Zielke, Henrik Lund Frandsen \\ Technical University of Denmark, Department of Energy Conversion and Storage, Ris $\varnothing$ Campus \\ Frederiksborgvej 399, P.O. Box 49, Building 779, 4000 Roskilde, Denmark \\ *University of Central Florida, Department of Mechanical and Aerospace Engineering \\ 12760 Pegasus Blvd, P. O. Box 162450, Orlando, FL 32816-2450
}

\begin{abstract}
Analyzing the thermo-mechanical reliability of solid oxide cell (SOC) stack requires precise measurement of the mechanical properties of the different components in the stack at operating conditions of the SOC. It is challenging to precisely characterize the time dependent deformational properties of metallic components in the SOC stacks at the required level of stress and operational conditions (high temperature and controlled atmosphere). This work presents an improved methodology for characterizing the time dependent or viscoplastic properties of metallic alloys used in SOC stacks at high temperature and in controlled atmosphere. The methodology uses a mechanical loading rig designed to apply variable as well as constant loads on samples within a gas-tight high temperature furnace. In addition, a unique remotely installed length measuring setup involving laser micrometer is used to monitor deformations in the sample. Application of the methodology is exemplified by measurement of stress relaxation, creep and constant strain rate behaviors of a high temperature alloy used in the construction of SOC metallic interconnects at different temperatures. Furthermore, measurements using the proposed methodology are also verified with literature and experiments conducted using other machines.
\end{abstract}

Key words: High temperature mechanical testing rig, Solid oxide fuel cells, Interconnects, Viscoplasticity

\footnotetext{
${ }^{1}$ Corresponding author:- Address: Frederiksborgvej 399, P.O. Box 49, Building 778, 4000 Roskilde, Denmark, Tele: +452074 5931, Fax: +45 4677 5858, e-mail: ttmo@dtu.dk
} 


\section{Introduction}

In the development of solid oxide fuel/ electrolysis cells or in general solid oxide cell (SOC) technologies, thermo-mechanical stability of the SOC stack components at operational conditions is vital to ensure their reliable performance [1-5]. In addition to the ceramic electrodes, the performances of auxiliary components such as metallic interconnects are highly affected by the thermal and chemical environment during the operation of the SOCs. A typical issue that is directly related to the structural stability of the metallic interconnect involves loss of contact, for example, in planar SOCs stack due to time dependent plastic deformations [1,2] and a weak interface between electrodes and the interconnect [6]. Loss of contact between the interconnect and planar electrodes is one of the problems that affects the reliability of outputs from SOC technologies $[1,2,7,8]$. Stresses generated due to thermal gradients in the SOC stack at operational conditions are often the main cause of plastic deformations in the interconnects, which may lead to possible loss of contact pressure at the interfaces of the stack components [7].

It is therefore important to characterize, analyze and theoretically model the high temperature deformational behaviors of metallic alloys used in the construction of SOC stacks in order to understand and improve their performance. In this regard, mechanical testing setups that are able to replicate the loading and atmospheric conditions during operation of the SOCs are needed. These conditions involve high temperatures (as high as $1000{ }^{\circ} \mathrm{C}$ ) and controlled atmospheres (e.g. hydrogen). In addition to a mechanism to apply the necessary level of load on test specimens, it is also beneficial for the experimental setup to have a methodology that can measure deformations in-situ.

Commercially, there are testing machines designed to allow the user perform thermo-mechanical analysis on test specimens. Some of these machines are provided with a mechanism to control the test atmosphere and temperature, but they have limitations with regards to the amount of force applied on the test specimens (e.g. maximum of $3 \mathrm{~N}$ force in the case of thermal mechanical analyzer or TMA supplied by Netzsch Gmbh, Germany) [9]. To increase the stress level, the cross sectional dimensions of the sample can be decreased, but this is limited by practicalities like machining and gripping of the specimens. Alternatively, in a bending test, the length and height of the sample can be designed to reach the maximum desired stress at a given mechanical load. However, for non-linear creep responses, e.g. power law creep and primary creep, the varying stress across the height of the sample makes it difficult to deconvolute the dependency on stress directly. This is far more directly measured in uniaxial tension experiments. 
Other testing machines have a larger load range with the ability to control the ambient temperature, but they are not supplied with a mechanism to control the atmosphere (e.g. Instron/MTS) [10]. Special gas tight furnaces can be designed for conventional mechanical test rigs, but as described in [11], this entails use of bellows or similar components, which introduce additional complications in load measurements (equalizing absolute pressures inside and outside).

In addition, while studying the creep behavior of high temperature alloys used specifically in SOCs, it is important to also consider the geometry of the final components. For instance in the case of fuel cell interconnects, where thin metallic plates typically are used, the grain growth over time is restrained by the thickness of the plate and the grain size significantly influences the creep rate. Thus, using round bars can provide results that are not representative of the material behavior in the SOFC stacks [12].

Previous studies on characterizing the time dependent deformations of metallic alloys used in SOC technologies often rely on conventional mechanical testing instruments with a heating furnace around the test sample. The time dependent strain measurements, for example, in the case of constant load creep test, are then performed after unloading, subsequent cooling to room temperature and taking the specimens from the testing equipment for length measurement $[8,13,14]$. This procedure is repeated several times depending on the required time resolution of the test data and test duration. The method is cumbersome, especially when performing long time creep tests, but care should also be taken when analyzing the result through several loading/unloading and heating/cooling steps. Because the thermal expansions now act on a modified geometry and thus changes for each thermal cycle.

Approaches to achieve in-situ load and displacement measurements for mechanical tests involving high temperature and controlled atmosphere have previously been presented by Frandsen et al. [11]. They used a camera to trace the deformation of SOFC anode supports through a porthole on a tube furnace to measure the deflection of the sample under four point bending [11]. The images are then analyzed to extract the position of the sample over time utilizing the known shape of the beam. A somewhat similar method together with a laser micrometer can be adapted to characterize the time dependent strain of samples loaded uniaxially. I.e. a laser micrometer can be setup in a way the laser beam is directed through a furnace to trace the change in the length of the sample loaded at high temperature and possibly in a controlled atmosphere. For uniaxial tension, higher precision is needed in the axial direction, as the deformations are much smaller. Thus in this work a laser micrometer, instead of an camera, is used. 
In this work a new high temperature mechanical testing setup is presented and verified. This setup allows for: 1) uniaxial loading resulting in a wide range of stress levels on a practical size of test samples (up to $300 \mathrm{~N}$ ), 2) control over test temperature (up to $900{ }^{\circ} \mathrm{C}$ ) and atmosphere and 3) precise in-situ measurement of deformations by use of a laser micrometer and in-situ measurement of load. The first and second requirements would help to fill the gap between commercially available creep testing machines with regards to range of load, temperature and gas control. The third feature is also added to enhance the accuracy of displacement measurement of the equipment. The control and data collection is performed by use of a computer program developed using LABVIEW ${ }^{\mathrm{TM}}$. Verification of the suggested experimental setup is also presented by various tests, comparison of the measurement results with those from literature and by using another instrument at room temperature. Section- 2 presents details of the experimental setup followed by verifications and use of the setup is discussed in Sections-3 and 4 respectively.

\section{Experimental setup}

The experimental setup is constructed in-house consisting of the following main components, see also Figures 1 and 2:

- A cross shaped and gas tight Kanthal tube with two horizontally placed portholes to allow a laser beam to be projected on the specimen through the furnace.

- A furnace around the gas-tight Kanthal tube.

- A cooling chamber, where load cells are placed, and which is directly connected with the gas tight tube.

- Two load cells (Model 41/000005, RDPE), which support the sample fixture to measure vertical loads.

- External actuator (Model ET32, Parker) acting through a sealing ring in the bottom of the cooling chamber.

- An externally installed laser micrometer (LSM-506, Mitutoyo) i.e. laser emitter and receiver for displacement measurement by beaming through the portholes.

- A display unit for the laser micrometer (LSM6200, Mitutoyo), which is used to set up, control and display readings from the laser micrometer.

- A fixture and sample holder manufactured from Inconel 600 and designed to apply uniaxial load on the sample. 


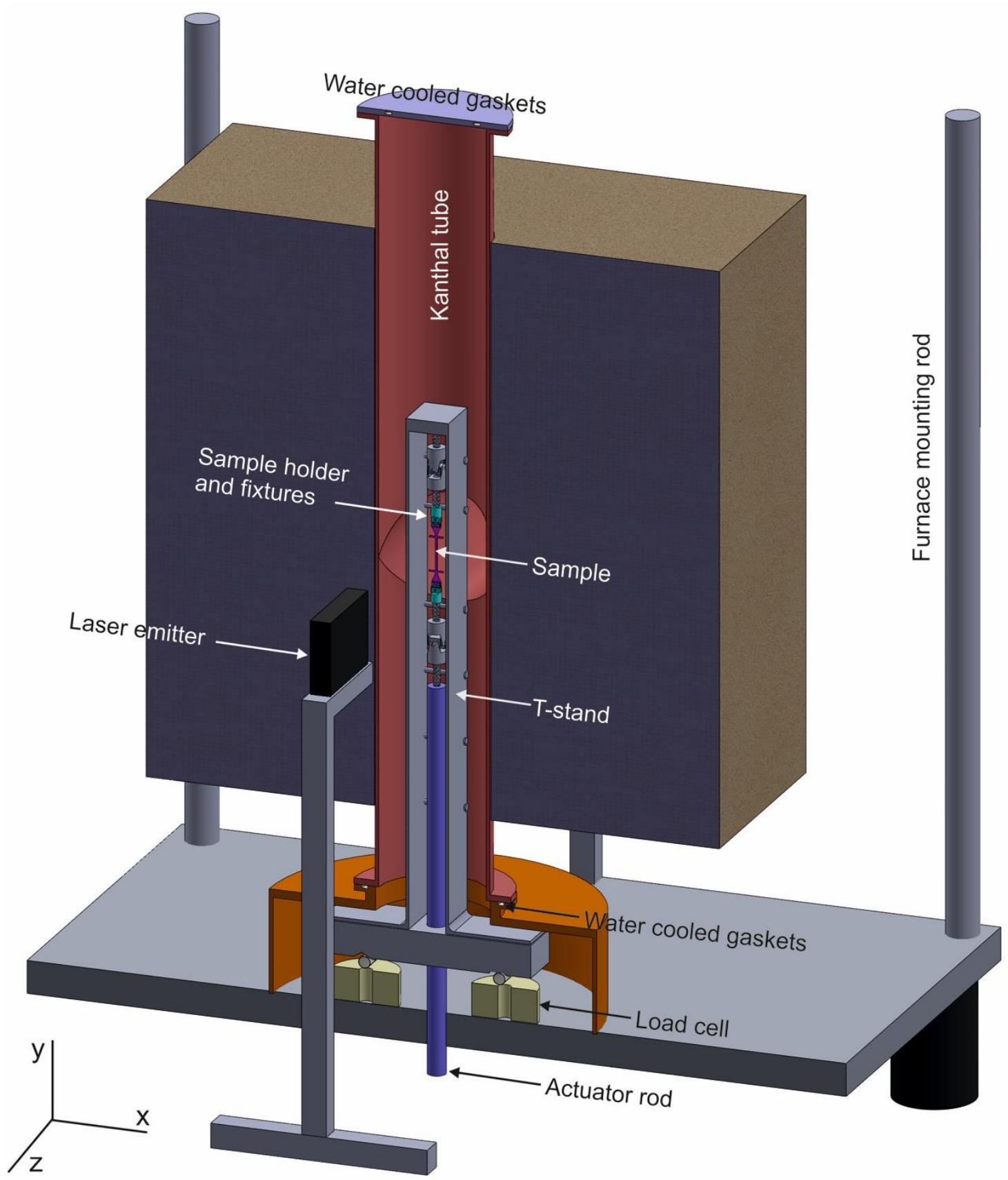

Fig 1: 3D schematic representation of the main parts of the experimental facility (sectional view).

The sample is mounted in a sample holder, which is fixed to a so-called T-stand. The T-stand rests on the load cells, and its upper fixed end is connected to the actuator through the sample. Moving the actuator will thus generate stress in the sample, which is balanced by the two load cells. The load cells are located in the cooling chamber, which shares the atmosphere with the heated Kanthal tube, and the load cells are thus within the gas-tight environment, see Figure 1. 
The combination of furnace and Kanthal tube can be moved up and down with the help of a furnace mounting rod in order to change samples. The laser emitter and receiver, constituting the laser scanning micrometer (LSM), are positioned in opposite direction of the furnace at the portholes allowing for the beam to pass through the furnace, see Figure 2. As shown by the 3D schematics in Figure 1, the LSM setup is also installed remotely from the loading mechanism having its own frame and horizontal rack to move and position it along the $x$-axis.

The heating furnace is constructed using Silicon carbide ( $\mathrm{SiC}$ ) electric heating elements and temperature control is achieved using a thermo-couple mounted on the Kanthal tube. The sample temperature is measured using a separate thermo-couple mounted close to the sample. Programing of furnace heating schedules is achieved using Eurotherm temperature controllers.

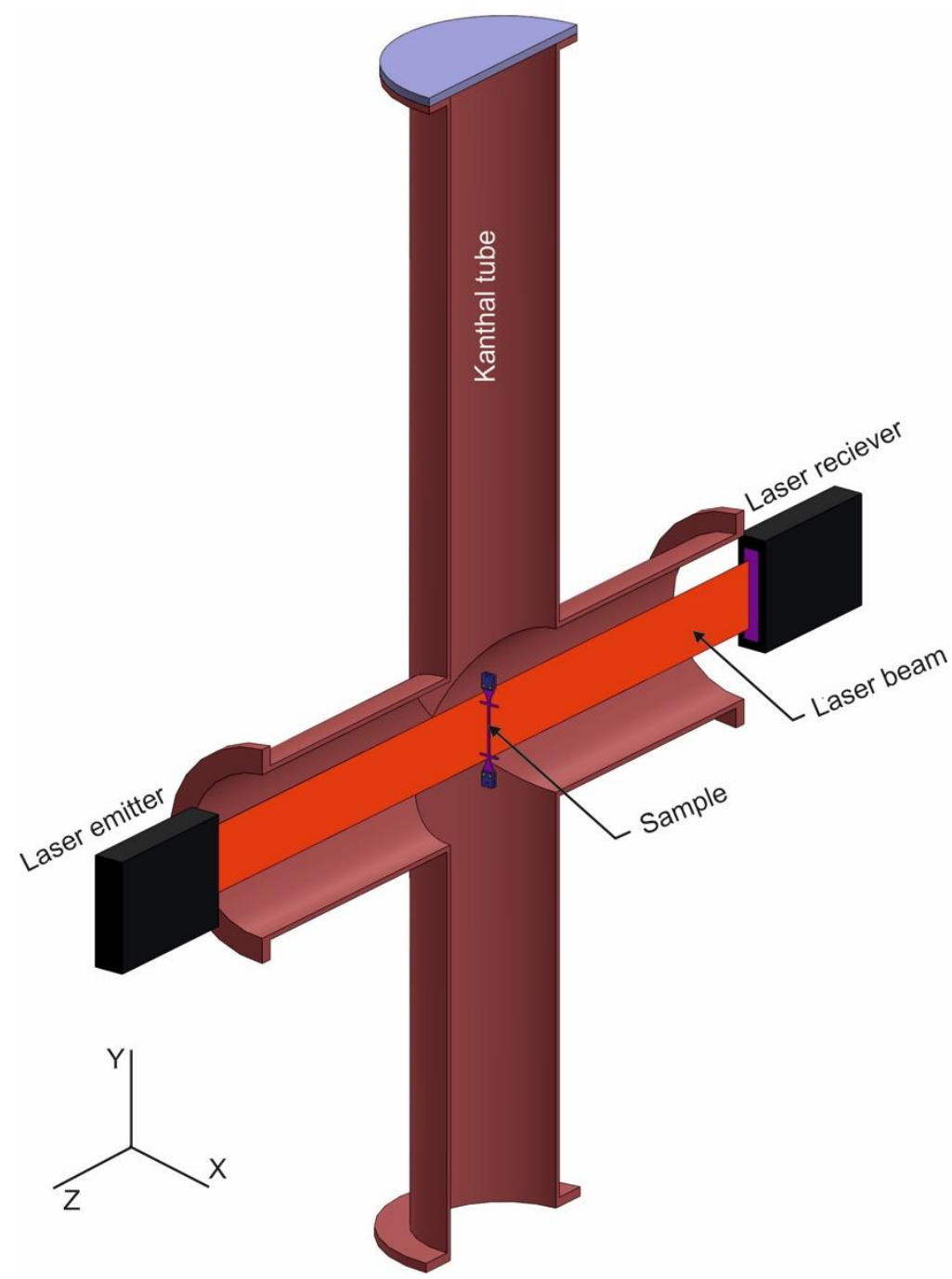

Fig 2: Schematic representation showing sectional view of the cross shaped Kanthal tube together with the positions of laser micrometer setup and test sample. 


\subsection{Sample geometry and sample holder}

Figure 3 (a) shows the sample geometry, which is chosen to achieve a maximum gauge length in relation to the LSM and in order to have distinct edges (crossbars) to track with the laser. The crossbars are intended to cast a shadow on the incoming laser beam (from LSM emitter) to the oppositely situated laser scanner (LSM receiver) of the LSM setup as shown in Figures 3 (b) and 5. During the experiment the elongation can therefore be traced by measuring the segment of the laser beam, which is between the crossbars (gauged part), see Section-2.3. Four holes in the sample remote from the gauged part of the sample are made to ensure there is no sliding between the sample and sample holder when applying the load. The length of the sample is chosen to match the height of the laser beam projected from the laser emitter, which is $70 \mathrm{~mm}$ in the case of the LSM used in this experimental setup.

(a)

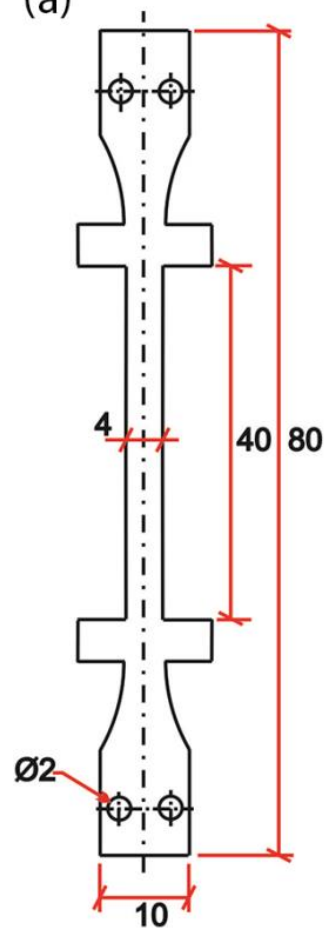

(b)

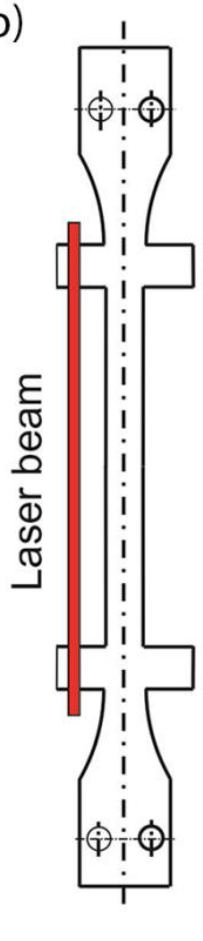

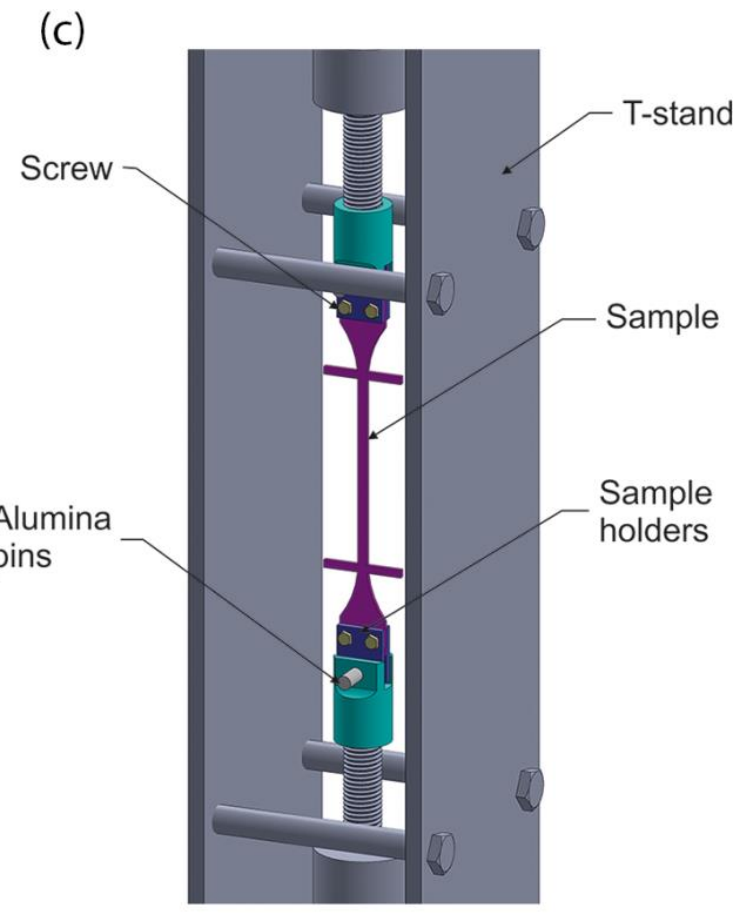

Figure 3: (a) Geometry of tensile and creep samples, (b) Sample with laser beam from LSM emitter and (c) Sample inside a sample holder and fixture (All the dimensions are in $\mathrm{mm}$ )

The sample holders are manufactured using Inconel 600 and consists of two plates designed to clamp the specimen in between, see Figure 3 (c). Clamping of the specimen to the sample holder is supported by screw and nut (made from stainless steel) that passes through the two holes on each side of the sample. This is designed to prevent any sliding between the specimen and the sample holder during loading. Since the holes on the sample are placed far away from the gauge section, any stress concentrations around the holes are too remote to have significant effect on the deformation of the gauge section. The sample 
holder is then fixed to the sample fixture and hence to the loading mechanism using two pins made of dense alumina allowing it to rotate freely and thereby centering the load along the axis of the specimen.

\subsection{Loading mechanism and sample fixture}

The loading mechanism and sample fixture are designed to apply uniaxial loads on the sample placed in a vertical position. The design of the sample fixture is made to practically avoid any bending moment/eccentricity due to possible vertical misalignment between the lower and upper sample holders during application of load. Figure 4 (a) - (c) shows the schematic representation of the loading mechanism and how the uniaxial load is applied using the actuator as well as direct hanging loads. The sample holder is designed to hold samples prepared from sheet metals. However, it can easily be changed depending on the material and dimensions of interest.

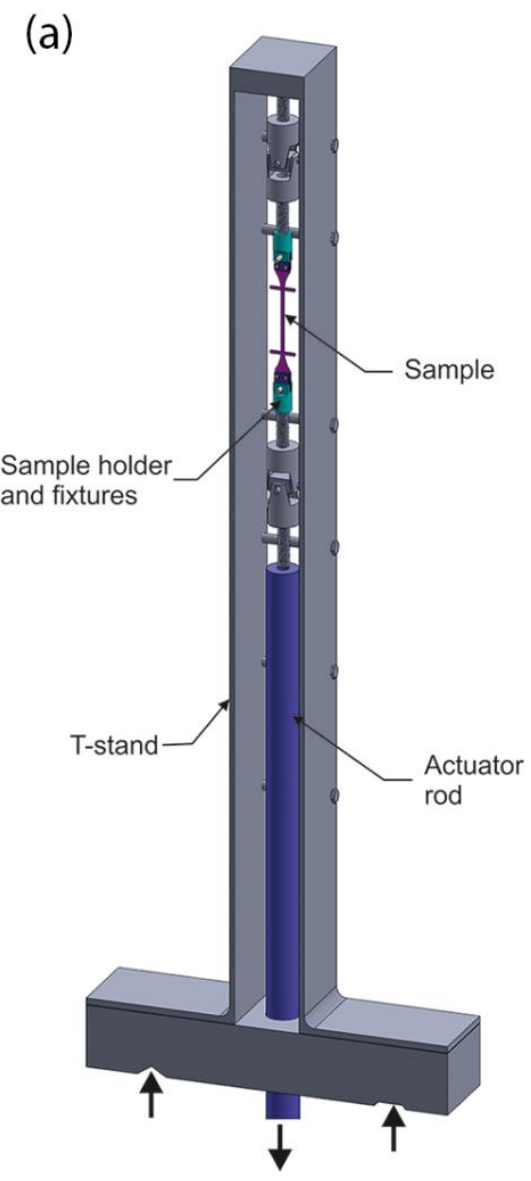

(b)

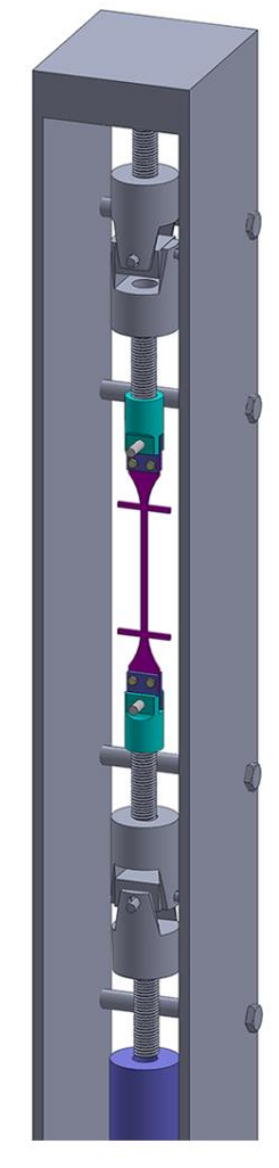

(c)

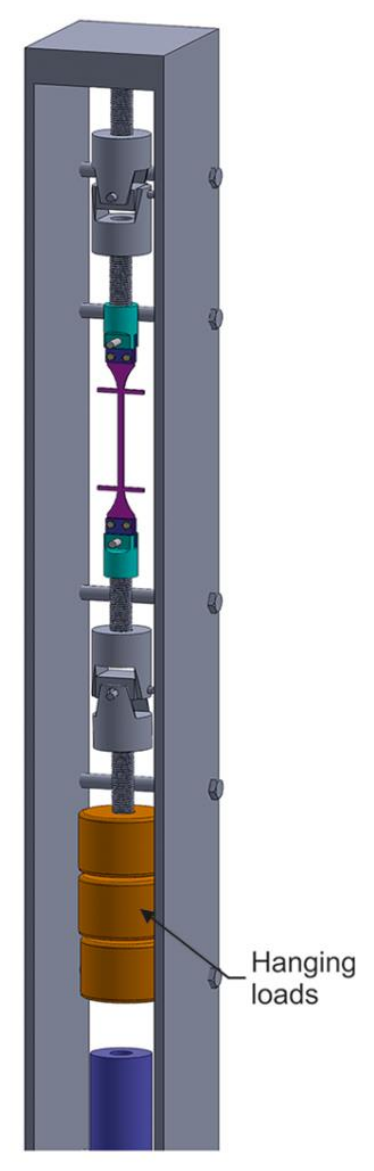

Fig 4: (a) Schematic representation of the loading mechanism, (b) Closer view of loading of the sample using the actuator and (c) Loading of sample using hanging loads.

The load can be generated either by moving the actuator downwards, see Figure 4 (b), or by hanging a load on the sample fixture, see Figure 4 (c). In either case, when a load is applied, the alumina pins holding 
the sample in the sample fixture move down, and the sample is put under an increasing or constant tensile stress. The load measurements by the load cells include weight of the T-stand and sample fixture mechanism, and these are simply subtracted from the measured value of the load. The small variation that may occur due to oxidation of the fixture can be neglected, as the load on the sample is far larger than the oxidation induced change. The arrangement of load cells and measurement of force using the load cells is similar to the system described in reference [11].

\subsection{Measurement of displacement}

The displacement can be estimated from the movement of the actuator, when this is used for inducing the load. Because the actuator has a digital gauge feeding back its position with an accuracy of approximately $0.1 \mu \mathrm{m}$. However, the actuator is connected to the sample through a long rod and loading fixtures. During loading, compliance of the various structures on the actuator rod connected to the sample affects the measurement of deformation making it difficult to achieve an accurate deformation measure of the sample. Furthermore, moving this rod in and out of the thermal field in the furnace exposes the long rod to various thermal expansions across the position of the rod (discussed further in [11]). Therefore, in this setup an externally installed laser micrometer is made to scan the positions of the upper and lower crossbars on the sample independent of the loading mechanism.

The LSM consists of a laser emitter, which emits a beam of laser into the furnace and hence to the sample through the portholes on the furnace. To protect the laser emitter and receiver from the high temperature in the furnace and ensure gas-tightness, the portholes are covered by windows mounted in water cooled gaskets. In addition, the LSM has a laser receiver installed at the opposite direction of the emitter (i.e. opposite side of the furnace) to receive the laser beam that passes through the furnace and thus also detect shadows from the specimen flanges. The receiver has the ability to detect changes to the laser beam, i.e. if obstacles are moving in front of the emitter. This is used to measure the elongation of the sample as described below.

A schematic representation that shows how the LSM works together with a sample geometry (discussed in Section-2.1) is shown in Figure 5. Note that the various segments of the laser beam arriving to the laser receiver are designated by their segment number, see Figure 5, and in the current case Seg-3 is of interest. For further details on segmentation and its setup, one can refer to the user manual for the Mitutoyo laser micrometer. 


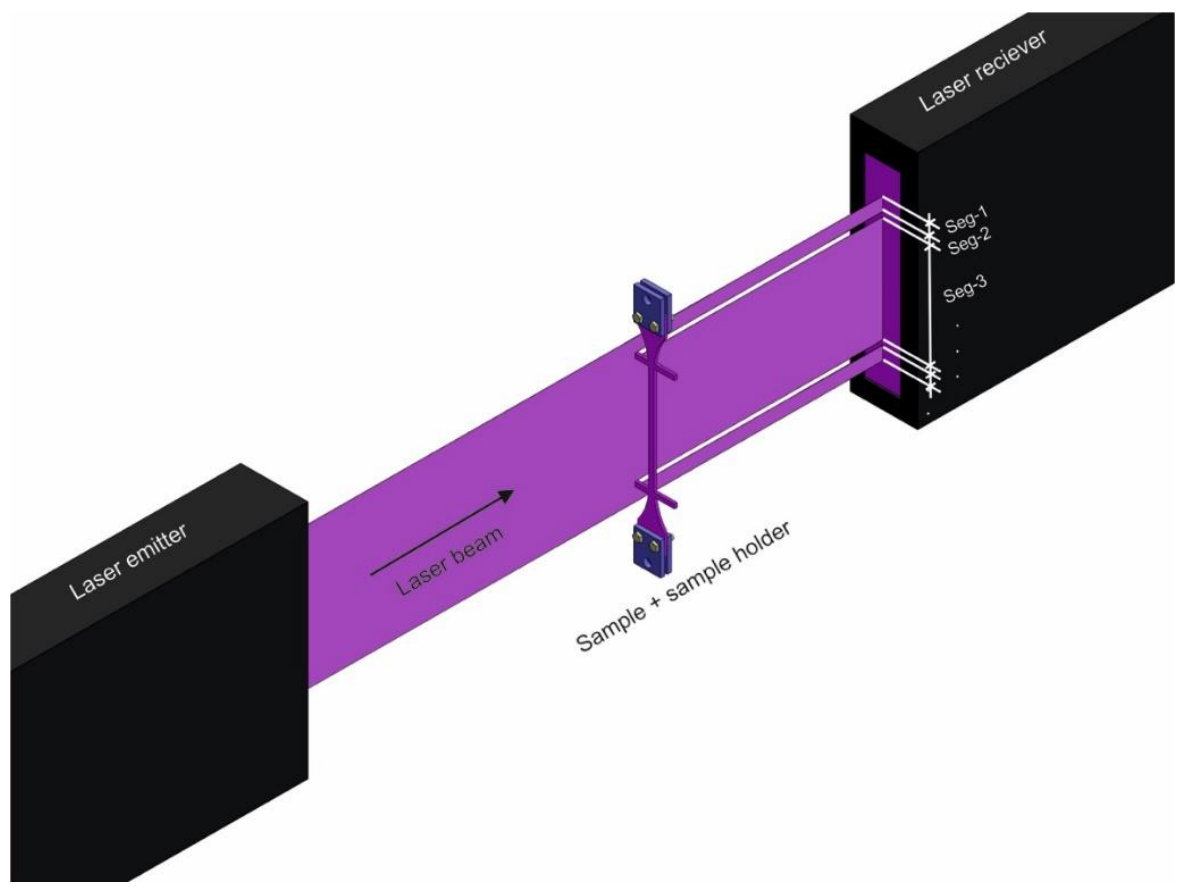

Fig 5: Schematic representation of laser beam projected on to the specimen and measured segments.

\section{Verification}

\subsection{Temperature measurements}

The accuracy of temperature measurement of the set-up is very important for mechanical testing at high temperature, as the material parameters are sensitive to temperature changes. To be able to verify this, temperature measurements from the furnace control thermo-couple are compared with the intended heating profile of the furnace or furnace-setting program. As shown in Figure 6, the temperature measurement from the set-up agrees well with the data from the furnace setting program with an absolute error less than $0.65^{\circ} \mathrm{C}$. 


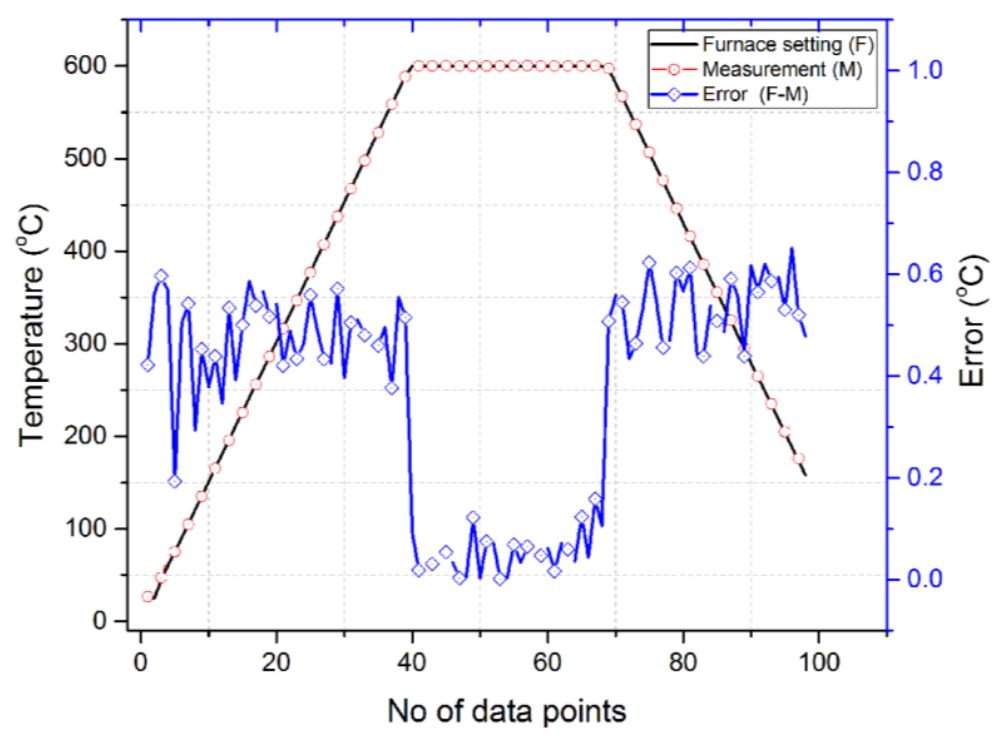

Fig 6: Comparison of temperature measurements with values from the furnace-setting program and the corresponding absolute error.

\subsection{Verification of displacement measurements}

With the laser beam projected through windows (with a glass protection) and a heated environment, the LSM is applied beyond its original specifications, and hence in the following the LSM is tested against known displacement measurements. A known change of length can be imposed with the help of the actuator, so the first verification is done by comparing the displacement measurements from the actuator movement and the laser micrometer.

For this purpose, the same arrangement of sample discussed above is used, however this time with the central part of the sample missing and the upper and lower crossbars disconnected from each other, see Figure 7 (a). Thus, the change of the displacement measure from both the LSM and the actuator should be identical.

During the experiment, the actuator is moved freely and data is collected both by the actuator digital gauge (recording the actuator position in time) as well as the LSM setup (recording the gap between the upper and lower crossbars). Comparison of displacement measures from the actuator and LSM setup is performed at three different conditions to investigate the effect of temperature and glass protection on the laser micrometer. These conditions include:

1. Testing at room temperature (RT) without laser micrometer protection glass

2. Testing at room temperature (RT) with laser micrometer protection glass in place

3. Testing at High temperature $\left(800^{\circ} \mathrm{C}\right)$ with laser micrometer protection glass in place 
The absolute change in length measured by the actuator, $U_{A C T}$, and the corresponding measure from the LSM, $U_{\text {LSM }}$, is collected for four tests involving different movements of the actuator for the same period of time. The average difference, $\Delta_{a}$, from the four tests between $U_{A C T}$ and $U_{L S M}$ at each time step is then calculated as:

$$
\Delta_{a}(t)=U_{A C T}-U_{L S M}
$$

Figure 7 (b) shows the average difference, $\Delta_{a}$, from four different tests for the above three types of test conditions. As shown in the figure, the difference between length measurements by the actuator and the LSM are almost independent of the glass protection unit as well as furnace temperature. In all the cases, the average difference is below $3 \mu \mathrm{m}$ which corresponds to less than $0.01 \%$ error on strain measured for a sample with an initial gauge length of $40 \mathrm{~mm}$. The mean error from all the tests is $1.7 \mu \mathrm{m}$ and the corresponding standard deviation is $0.5 \mu \mathrm{m}$. There is little deviation between the measurements done at the three conditions, and the length measurement method can thus be concluded to be precise at all conditions.
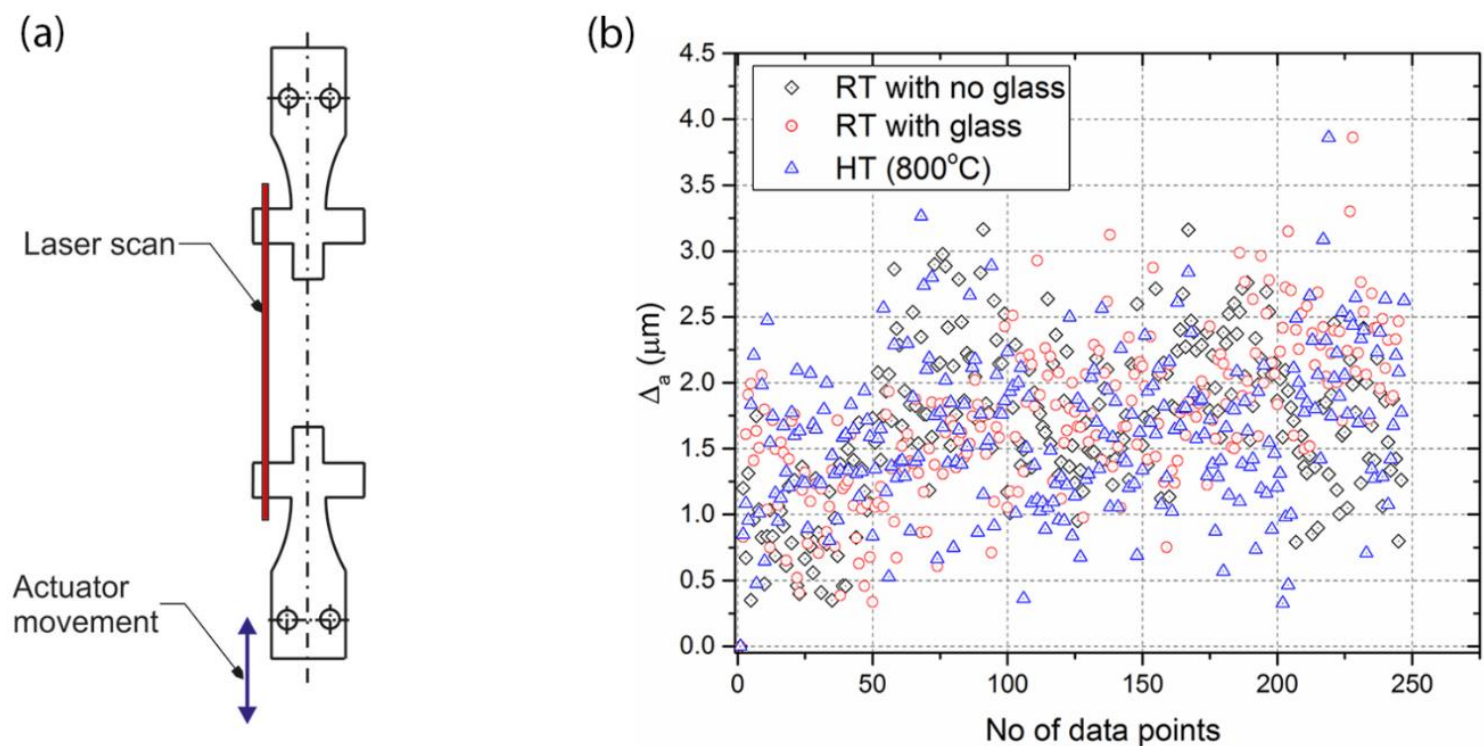

Fig 7: (a) Specimen set-up to verify the LSM setup against actuator movement, (b) Mean difference between the measurements from the LSM setup and actuator gauge.

\subsection{Verification of the overall setup}

This section presents verification of the accuracy of measurements conducted using the proposed experimental setup. For this purpose, results from the current experimental setup are compared with experimental data from literature as well as experiments conducted using other mechanical testing 
machines. In the current study, samples are prepared from stainless steel (Crofer 22 APU) supplied in the form of cold-rolled and annealed plates with a thickness of $0.3 \mathrm{~mm}$. This is one of the metallic alloys commonly used for SOC interconnectors. Using the proposed test set up, the deformational behavior of Crofer $22 \mathrm{APU}$ at constant strain rate and its elastic modulus at different temperatures are measured for comparison.

The elastic parameters of Crofer $22 \mathrm{APU}$, particularly the Young's modulus, $E$, is determined using monotonic loading of the sample at the given temperature. For uniaxial loading of the samples considered in this study, the slope in the linear (elastic) part of stress, $\sigma$, versus strain, $\varepsilon$,curve is calculated after loading samples with a stroke rate of $1.25 \mathrm{~mm} / \mathrm{min}$ at different temperatures. As discussed in reference[15], the stroke rate is assumed to be fast enough to minimize the effect of creep at high temperatures.

$$
E=\frac{\Delta \sigma}{\Delta \varepsilon}
$$

Multiple loading tests are performed to estimate the Young's modulus from the load and deformation data. Figure 8 shows an example of stress versus strain plot with the corresponding fitting curves for Crofer $22 \mathrm{APU}$ at $700{ }^{\circ} \mathrm{C}$ (the curves are displaced by $0.025 \%$ for each successive measurement). Linear trends are observed at each loading cycle, indicating that no plastic deformations are present.

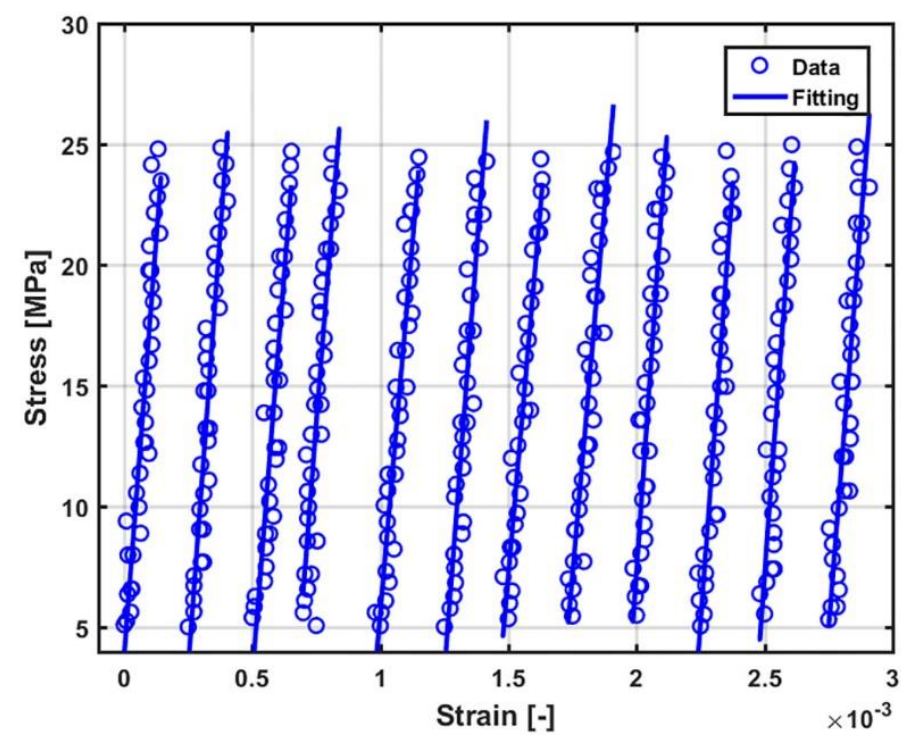

Fig 8: Example of stress versus strain plots together with fitting curves to determine Young's modulus. 
Comparison of results from the current study, see Table 1, are found to be consistent with the previously reported values by Chiu et al. [8] and the material data provided by, ThyssenKrupp VDM, the manufacturer of Crofer $22 \mathrm{APU}$ [16] for temperatures up to $600{ }^{\circ} \mathrm{C}$. However, for higher temperatures, Chiu et $a l$. have reported lower values than what have been obtained in this study. This may have been caused by influence of plastic deformation, as the yield strength of Crofer 22 APU drops drastically above $600{ }^{\circ} \mathrm{C}$ [8]. This is also supported by Boccaccini et al., who reported a higher value of Young's modulus for the same material using an impulse excitation technique at $700{ }^{\circ} \mathrm{C}$ [17].

Table 1: comparison of Young's modulus results with literature

\begin{tabular}{cccc}
\hline Temperature & \multicolumn{3}{c}{ Young's Modulus (GPa) } \\
\cline { 2 - 4 }$\left({ }^{\circ} \mathrm{C}\right)$ & This work & Ref [8] & Ref [16] \\
\hline 25 & $222 \pm 3.1$ & 214 & 220 \\
200 & $212 \pm 2.2$ & - & 210 \\
400 & $180 \pm 3.4$ & 184 & 195 \\
600 & $149 \pm 5.2$ & 162 & - \\
700 & $128 \pm 8.5$ & 91 & - \\
800 & $75 \pm 7.5$ & 44 & - \\
\hline
\end{tabular}

In addition, the constant strain rate behavior of Crofer 22 APU at room temperature is measured using a commercial testing machine (Electromechanical material testing machine, Zwick/Roell Z030, Zwick GmbH \& Co.KG). Figure 9 shows a comparison between stress-strain curves collected from the experimental setup suggested in this study with that of measured from the commercial testing machine. Results from the suggested setup agree well with the measurements collected from the Zwick/Roell machine.

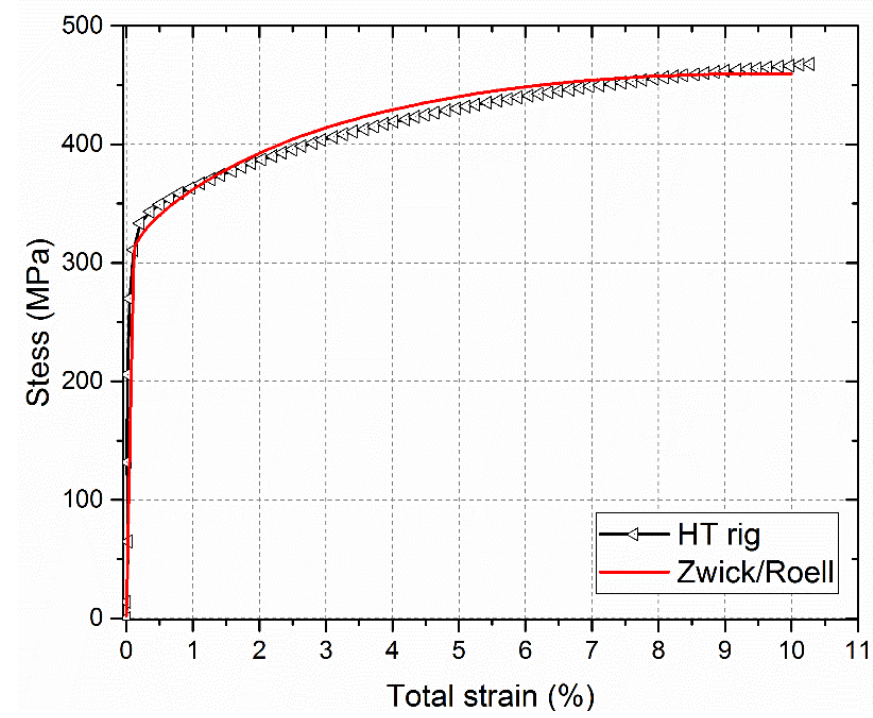

Figure 9: Comparison of constant strain rate behavior at room temperature [stroke rate $=2 \mathrm{~mm} / \mathrm{min}$ ]. 
Finally, the reliability of the experimental setup while measuring loads and displacements in the sample at high temperature is also tested by performing different kinds of loadings under similar conditions. Figure 10 shows a comparison of stress-strain curves during monotonic and cyclic (loading and unloading) loadings on a sample of Crofer $22 \mathrm{APU}$ at $700^{\circ} \mathrm{C}$ using a stroke rate of $0.12 \mathrm{~mm} / \mathrm{min}$. It was possible to reproduce a fairly similar maximum or saturation stress of Crofer 22 APU at the given temperature using different types of loading. Generally, the maximum difference in saturation stress from the two tests is less than $1.5 \%$. Note that since the saturation stress of Crofer $22 \mathrm{APU}$ at $700{ }^{\circ} \mathrm{C}$ remains fairly constant over several cycles of loading, it can be taken as a reproducibility test for the measurement setup.

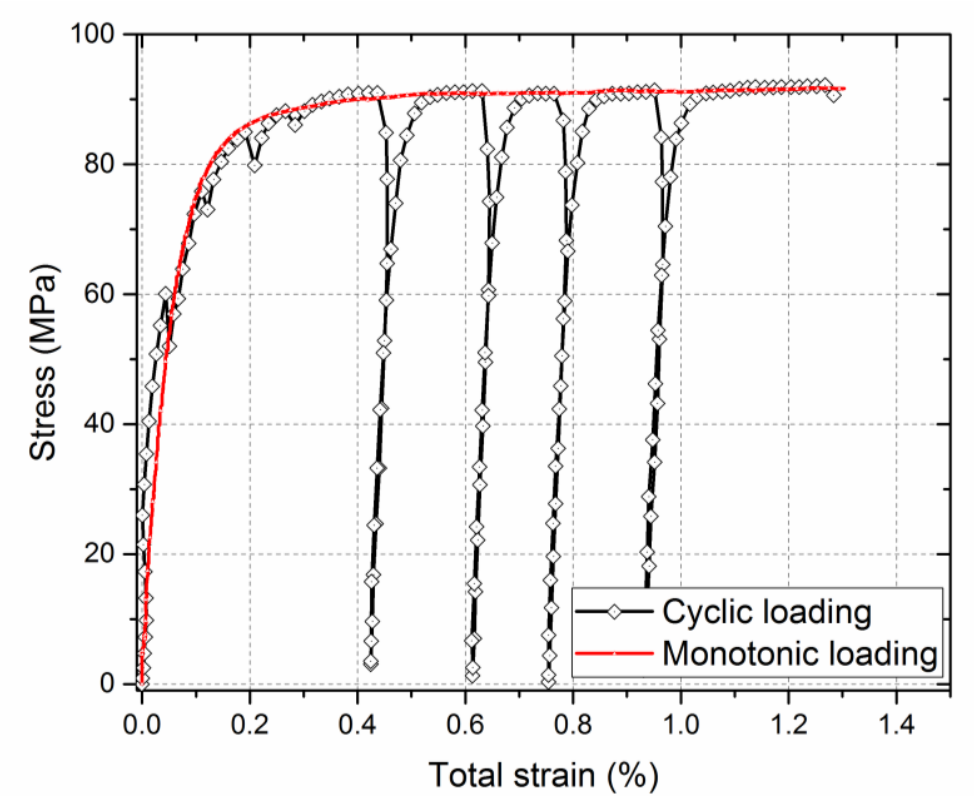

Figure 10: Comparison of stress vs strain curves for Crofer 22 APU during monotonic and cyclic loading at $700{ }^{\circ} \mathrm{C}$ [stroke rate $=0.12 \mathrm{~mm} / \mathrm{min}$ ]

Results shown in Table 1 as well as Figure 9 and 10 show the capability of the experimental setup developed in this study. Therefore, the developed setup can efficiently help to characterize the deformational behaviors of high temperature metallic alloys under their operational conditions. By modifying the sample holder mechanisms, the same system can also be used to study the performance of ceramic materials at high temperatures and controlled atmospheres.

\section{Application of the methodology for SOC metallic interconnects}

To illustrate the capability of the setup described in this study, experiments to characterize the viscoplastic behavior of a high chromium ferritic stainless steel, Crofer 22 APU, are conducted. Details about the alloy contents of the material can be found in the work reported by Chiu et al.[8]. Crofer 22 APU is typically used for metallic interconnects (MICS) for solid oxide fuel cell stacks operating under intermediate 
temperatures $[7,8,13,14]$. It has been reported by various authors that failure in the MICs due to time dependent inelastic deformation during operation of SOFC has significant effect on the reliability of the entire SOFC stack $[2,7,8,18-20]$. Hence precise characterization of the time dependent (viscoplastic) behavior of these materials at operational conditions of SOFCs is important. In this study, high temperature mechanical tests involving constant strain rate loading, stress relaxation as well as creep experiments are conducted so as to characterize the viscoplastic behavior of Crofer 22 APU using the experimental setup described in Section-2.

During all the high temperature tests, first the temperature of the furnace is set to the required isothermal testing temperature. Heating of the furnace to the required temperature is performed using a heating rate of $6^{\circ} \mathrm{C} / \mathrm{min}$. During ramping of the furnace temperature, the sample as well as the overall loading mechanism experiences thermal expansion and this could impose an unnecessary load on the sample before the test conditions are reached. To avoid any loading on a sample due to thermal expansion while ramping of the furnace temperature, the sample and loading mechanism are pushed up in a way to allow a vertical free movement during thermal expansion. Once the furnace has reached the required temperature, it is kept constant for half an hour before applying force. This is intended to stabilize the thermal distribution around the sample before applying any load.

\subsection{Constant strain rate test}

One of the tests that can be performed using the experimental setup suggested in this work is to characterize the constant strain rate behavior. To perform such tests, a loading fixture attached to the actuator, see Figure $4(a)$ is used. The constant strain rate tests were conducted using actuator stroke rate of $0.12 \mathrm{~mm} / \mathrm{min}$. During loading, the change in length of the sample and total load from the load cells are recorded simultaneously.

Figure 11 (a) presents the constant strain rate behavior of Crofer 22 APU at temperatures between 25 and $800{ }^{\circ} \mathrm{C}$ and using stroke rate of $0.12 \mathrm{~mm} / \mathrm{min}$. This corresponds to, for example, an actual specimen strain rate of $2.51 \times 10^{-4} 1 / \mathrm{s}$. These kinds of results do not only show the softening of the material with temperature, but also they are necessary to characterize the hardening in the materials at the respective temperatures after the onset of plastic deformation. For instance, the stress-strain curves in the case of 700 and $800{ }^{\circ} \mathrm{C}$ saturate quickly once the deformation enters the plastic regime, whereas those below $700{ }^{\circ} \mathrm{C}$ show a gradual hardening as the material deforms plastically. This property of Crofer 22 APU determines its transient/primary creep behavior of interconnects during the various operational cycles of SOFCs[15]. The high temperature stress-strain curves are almost consistent with the material data sheet 
provided by the manufacturer of Crofer 22 APU [16]. The observed differences are presumed to be due to the rate of loading of the samples.

\subsection{Stress relaxation tests}

Using the same sample fixture that has been used for constant strain rate test, it is possible to stretch the specimen to the required level of constant strain and allow the stress in the material to relax over time. In this work, the relaxation tests were conducted following loading of the sample with a faster stroke rate ( $1 \mathrm{~mm} / \mathrm{min}$ ) initially and keeping the constant deformation over time. To avoid any hardening during loading, the samples were stretched to a constant displacement where the initial stress before relaxation is below the $0.2 \%$-proof stress (stress at $0.2 \%$ of strain) of the material at the respective temperature. Figure 11 (b) shows the stress relaxation properties of Crofer 22 APU at different temperatures between 200 and $800{ }^{\circ} \mathrm{C}$. The corresponding initial stresses at the start of relaxation are $53 \mathrm{MPa}, 50 \mathrm{MPa}, 51 \mathrm{MPa}$, $47 \mathrm{MPa}$ and $43 \mathrm{MPa}$ respectively.

(a)

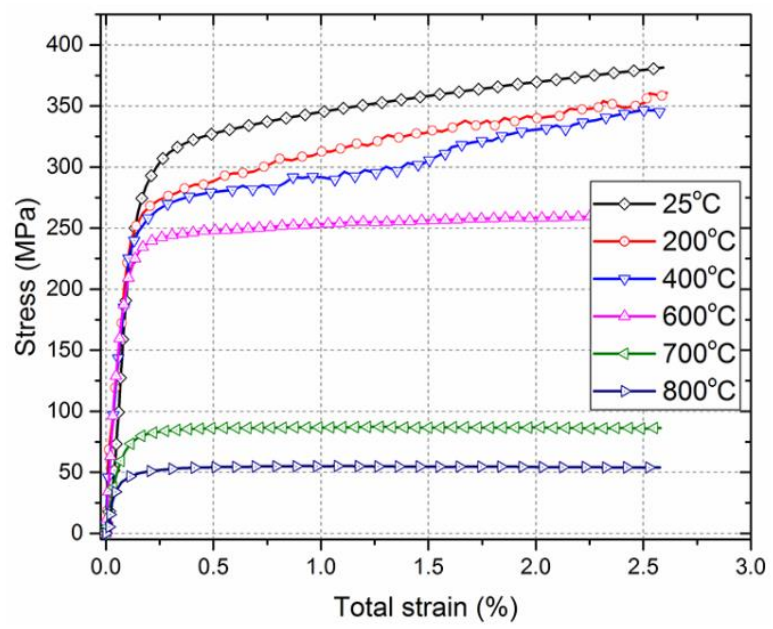

(b)

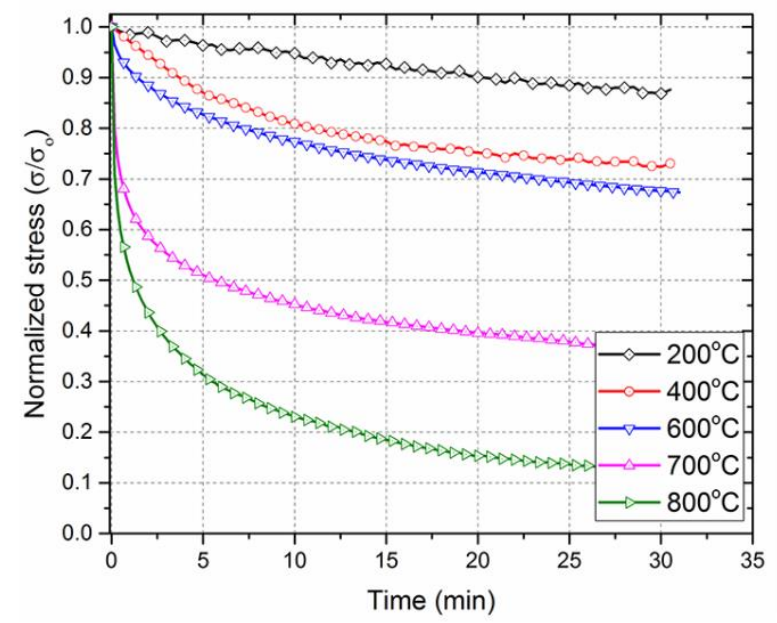

Figure 11: (a) Comparison of constant strain rate behavior of Crofer 22 APU at different temperatures

[stroke rate $=0.12 \mathrm{~mm} / \mathrm{min}$ ] (b) Relaxation behavior of Crofer $22 \mathrm{APU}$ at different temperatures

\subsection{Creep test}

During creep tests, a constant force is applied on the sample using hanging dead loads, see Figure 4 (b), and the corresponding deformation in time is measured using the laser micrometer. The dead loads are made from dense alumina and they are attached to the sample holder by a rod going through the center of the loads, see Figure 4 (c). During heating to the required temperature, the hanging loads were supported by a plate mounted on the top of the actuator rod, and thus no load is applied to the sample. Once the furnace is heated to the required temperature, it was allowed to remain at that temperature for 
$30 \mathrm{~min}$ before applying the load. The load is applied on the sample by moving the actuator rod and support plate down, such that loads are hanging on the sample. After the load is activated, the deformation of the sample is recorded in time using the laser micrometer.

Since the measurement of deformation in the sample is started few seconds after the application of the load, and hence after elastic deformation, It can be assumed that the total deformation in the sample is attributed to creep (viscoplasticity). Figure 12 shows creep strain measurements in time for Crofer 22 APU at 600 and $700{ }^{\circ} \mathrm{C}$ at two levels of stresses.

(a)

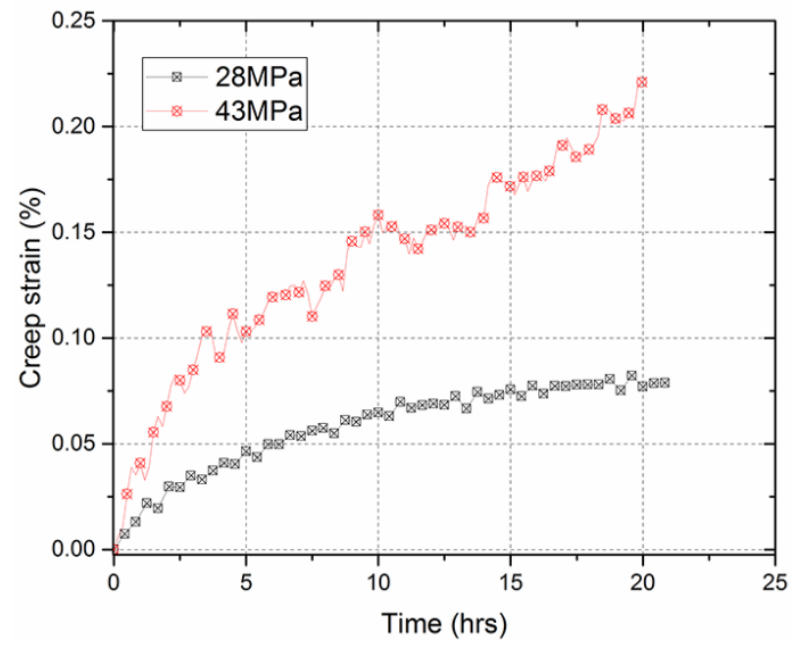

(b)

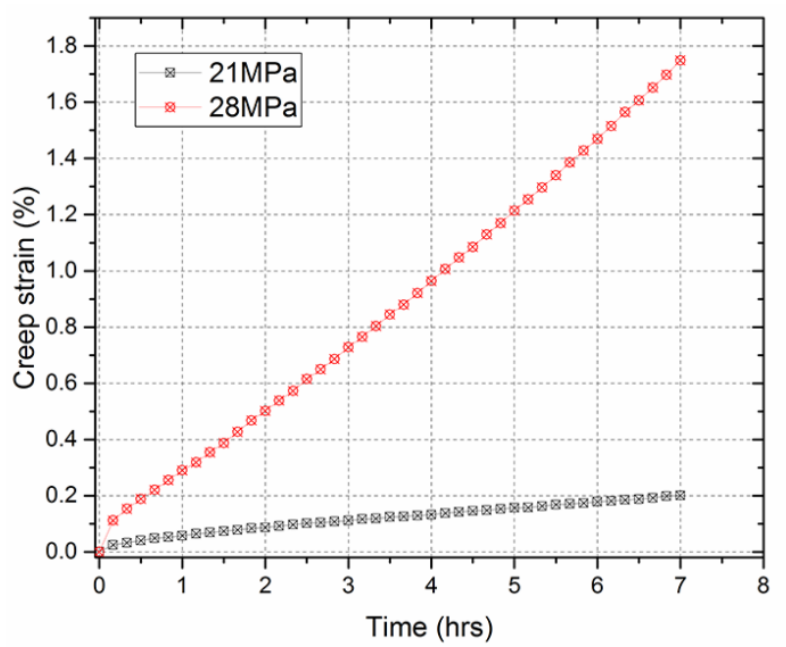

Figure 12: Creep behavior of Crofer $22 \mathrm{APU}$ at (a) 600 and (b) $700{ }^{\circ} \mathrm{C}$

\section{Conclusions}

Improving the mechanical reliability of devices operating at high temperature and specific atmospheres as solid oxide cell (SOC) stacks requires precise measurement of the mechanical properties of the different components at the given operating conditions. This work presents a novel experimental device for characterization of the mechanical material properties and in particular the viscoplastic properties at high temperature and in controlled atmosphere.

The experimental device permits in-situ mechanical load measurements, contactless displacement measurements, while controlling atmosphere and temperature. The load cells are placed in the same atmosphere as the specimens allowing frictionless measurement of the load. This can be accomplished by use of the right thermal management in the rig. Different loading mechanisms for constant displacement rate, relaxation and creep experiments needed for characterization of viscoplastic behavior 
are shown. For the displacement measurements a novel method using an externally installed laser micrometer is used to monitor deformations of the sample.

The application of the methodology is exemplified by measurement of the relaxation, creep and constant strain rate behaviors of metallic interconnects for SOCs at 600,700 and $800{ }^{\circ} \mathrm{C}$. Furthermore, measurements using the proposed methodology are validated using results from literature as well as experiments at room and high temperature.

\section{Acknowledgements}

The research leading to these results has received funding from the European Union's Seventh Framework Programme (FP7/2007- 2013) for the Fuel Cells and Hydrogen Joint Technology Initiative under grant agreement no 325278 and from Energinet.dk under the Public Service Obligation, ForskEL contract 20141-12236. The authors would also appreciate the support of John Johnson from the department of Energy conversion and storage, Technical university of Denmark. 


\section{References}

[1] A. Nakajo, Z. Wuillemin, J. Van herle, D. Favrat, Simulation of thermal stresses in anodesupported solid oxide fuel cell stacks. Part I: Probability of failure of the cells, J. Power Sources. 193 (2009) 203-215. doi:10.1016/j.jpowsour.2008.12.050.

[2] A. Nakajo, Z. Wuillemin, J. Van herle, D. Favrat, Simulation of thermal stresses in anodesupported solid oxide fuel cell stacks. Part II: Loss of gas-tightness, electrical contact and thermal buckling, J. Power Sources. 193 (2009) 216-226. doi:10.1016/j.jpowsour.2008.12.039.

[3] M. Peksen, 3D thermomechanical behaviour of solid oxide fuel cells operating in different environments, Int. J. Hydrogen Energy. 38 (2013) 13408-13418.

doi:10.1016/j.ijhydene.2013.07.112.

[4] M. Peksen, Numerical thermomechanical modelling of solid oxide fuel cells, Prog. Energy Combust. Sci. 48 (2015) 1-20. doi:10.1016/j.pecs.2014.12.001.

[5] M. Peksen, 3D transient multiphysics modelling of a complete high temperature fuel cell system using coupled CFD and FEM, Int. J. Hydrogen Energy. 39 (2014) 5137-5147. doi:10.1016/j.ijhydene.2014.01.063.

[6] Z. Lu, G. Xia, J.D. Templeton, X. Li, Z. Nie, Z. Yang, J.W. Stevenson, Development of Ni1-xCoxO as the cathode/interconnect contact for solid oxide fuel cells, Electrochem. Commun. 13 (2011) 642-645. doi:10.1016/j.elecom.2011.03.034.

[7] T.T. Molla, K. Kwok, H.L. Frandsen, Efficient modeling of metallic interconnects for thermo- - mechanical simulation of SOFC stacks : homogenized behaviors and effect of contact, Int. J. Hydrogen Energy. 41 (2016) 6433-6444. doi:10.1016/j.ijhydene.2016.03.002.

[8] Y.T. Chiu, C.K. Lin, J.C. Wu, High-temperature tensile and creep properties of a ferritic stainless steel for interconnect in solid oxide fuel cell, J. Power Sources. 196 (2011) 2005-2012. doi:10.1016/j.jpowsour.2010.09.083.

[9] H.J. Moltzan, Thermomechanical Analysis (TMA), 1993. doi:10.1016/B978-0-7506-9267-0.500405.

[10] Material Testing Systems, MTS 810 \& 858 Material Testing Systems, 2006.

[11] H.L. Frandsen, D.J. Curran, S. Rasmussen, P.V. Hendriksen, High throughput measurement of high temperature strength of ceramics in controlled atmosphere and its use on solid oxide fuel cell anode supports, J. Power Sources. 258 (2014) 195-203. doi:10.1016/j.jpowsour.2014.02.036.

[12] S. Ukai, T. Okuda, M. Fujiwara, T. Kobayashi, S. Mizuta, H. Nakashima, Characterization of High Temperature Creep Properties in Recrystallized 12Cr-ODS Ferritic Steel Claddings, J. Nucl. Sci. Technol. 39 (2002) 872-879. doi:10.1080/18811248.2002.9715271.

[13] B. Kuhn, M. Talik, L. Niewolak, J. Zurek, H. Hattendorf, P.J. Ennis, W.J. Quadakkers, T. Beck, L. Singheiser, Development of high chromium ferritic steels strengthened by intermetallic phases, Mater. Sci. Eng. A. 594 (2014) 372-380. doi:10.1016/j.msea.2013.11.048.

[14] B. Kuhn, C.A. Jimenez, L. Niewolak, T. Hüttel, T. Beck, H. Hattendorf, L. Singheiser, W.J. 
Quadakkers, Effect of Laves phase strengthening on the mechanical properties of high $\mathrm{Cr}$ ferritic steels for solid oxide fuel cell interconnect application, Mater. Sci. Eng. A. 528 (2011) 5888-5899. doi:10.1016/j.msea.2011.03.112.

[15] T.T. Molla, K. Kwok, H.L. Frandsen, Transient deformational properties of high temperature alloys used in solid oxide fuel cell stacks, J. Power Sources. 351 (2017) 8-16. doi:10.1016/j.jpowsour.2017.03.059.

[16] Thyssenkrupp VDM, Crofer 22 APU Material data sheet no. 4046, 2010.

[17] D.N. Boccaccini, H.L. Frandsen, B.R. Sudireddy, P. Blennow, Å.H. Persson, K. Kwok, P. Vang Hendriksen, Creep behaviour of porous metal supports for solid oxide fuel cells, Int. J. Hydrogen Energy. 39 (2014) 21569-21580. doi:10.1016/j.ijhydene.2014.07.138.

[18] A. Nakajo, F. Mueller, J. Brouwer, J. Van Herle, D. Favrat, Mechanical reliability and durability of SOFC stacks. Part II: Modelling of mechanical failures during ageing and cycling, Int. J. Hydrogen Energy. 37 (2012) 9269-9286. doi:10.1016/j.ijhydene.2012.03.023.

[19] A. Nakajo, F. Mueller, J. Brouwer, J. Van Herle, D. Favrat, Mechanical reliability and durability of SOFC stacks. Part I: Modelling of the effect of operating conditions and design alternatives on the reliability, Int. J. Hydrogen Energy. 37 (2012) 9249-9268. doi:10.1016/j.ijhydene.2012.03.043.

[20] C.K. Lin, T.T. Chen, Y.P. Chyou, L.K. Chiang, Thermal stress analysis of a planar SOFC stack, J. Power Sources. 164 (2007) 238-251. doi:10.1016/j.jpowsour.2006.10.089. 